\title{
Human epidermal growth factor for the stratificatio
of synovial lining layer and neovascularisation in rheumatoid arthritis
}

\author{
SHUNICHI SHIOZAWA, ${ }^{1}$ KAZUKO SHIOZAWA, ${ }^{1}$ YASUSHI TANAKA, \\ IPPEI MORIMOTO,${ }^{1}$ MASAHITO UCHIHASHI, ${ }^{1}$ TAKUO FUJITA ${ }^{1}$ \\ KAZUSHI HIROHATA, ${ }^{2}$ YUKIO HIRATA, ${ }^{3}$ AND SHIGEAKI IMURA ${ }^{4}$
}

From the Departments of ${ }^{1}$ Medicine and ${ }^{2}$ Orthopaedic Surgery, Kobe University School of Medicine, Kobe the ${ }^{3}$ National Cardiovascular Center, Osaka; and the ${ }^{4}$ Kakogawa National Hospital, Kakogawa, Japan

SUMMARY Immunohistochemical study showed selective localisation of human epidermad growth factor (hEGF) to the synovial lining layer. Although the synovial lining layer of the rheumatoid, osteoarthritic, and traumatic joints was hEGF positive, hEGF staining was especially dense at the rheumatoid synovial lining layer; the staining increasing linearly according to the degree of stratification of the lining layer $(r=1)$. Human epidermal growth factor was ultrastructurally localised to cytoplasm, especially to rough endoplasmic reticulum, of the

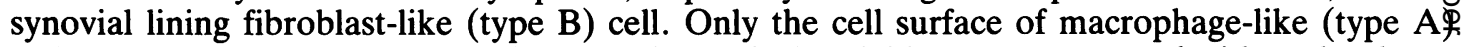
cells was hEGF positive. When different histological variables were compared with each othed $\vec{b}$ positive correlation was found between hEGF staining of the synovial lining layer and the degere of neovascularisation of rheumatoid synovium $(r=0.72)$. Although some lymphocytes were weakly hEGF positive, neovascularisation did not correlate with the extent of lymphoct infiltration or of hEGF staining of lymphocytes. Lymphocyte infiltration or hEGF staining of lymphocytes did not correlate with hEGF staining of the synovial lining layer, whereas the lymphocyte infiltration correlated positively with the extent of perivascular accumulation o\$ lymphocytes $(\mathrm{r}=0 \cdot 89)$. These findings suggest that $(a)$ hEGF is synthesised by and secretef through endoplasmic reticulum and Golgi apparatus from the synovial lining type B cells (b) hEGF is at least partially responsible for the pathogenesis of stratification of the rheumatoif synovial lining layer, and perhaps of neovascularisation of the rheumatoid synovium, whereas is not responsible for lymphocyte accumulation to the rheumatoid synovium.

Stratification of the synovial lining layer ${ }^{12}$ and periarticular osteoporosis ${ }^{34}$ are both early, characteristic manifestations of rheumatoid arthritis, but few detailed studies have been carried out to elucidate their pathogenesis. In particular, information about the factor(s) responsible for the stratification of the synovial lining layer is not available. In this study we have focused on human epidermal growth factor (hEGF), which is a 53 amino acid polypeptide essential for cell growth in a variety of tissue. ${ }^{5}$ It stimulates bone resorption in neonatal mouse calvaria in vitro, ${ }^{6}$ and specific receptors for

Accepted for publication 23 January 1989.

Correspondence to Dr Shunichi Shiozawa, Department of Medicine, Third Division, Kobe University School of Mecicine, 7-5 Kusunoki-cho, Chuo-ku, Kobe, Japan.
hEGF are present in murine and human bonê tissues. ${ }^{7-9}$

As synovial lining cells express HLA-DR antige on their surface, ${ }^{10-13}$ and synovial adherent cells ares indeed immunologically active, presenting antige to $\mathrm{T}$ cells, ${ }^{14-16}$ it is expected that synovial lining cellsu play an important part in initiating the immune response in the synovial membrane, and in this was may contribute to the pathogenesis of chronie synovitis. Observation that the stratification synovial lining layer represents the early, charactero istic manifestation of the disease ${ }^{12}$ supports thi possibility. There are, however, still questions abouf the origin and functional characteristics of both the synovial lining macrophage-like cells (type A) an

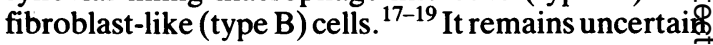


whether the synovial lining type A and B cells are mutually transitional or not, ${ }^{13}$ 19-23 though at present it appears likely that synovial type A cell is of bone marrow origin. ${ }^{24} 25$ It is unclear also whether synovial lining type $B$ cells are similar to fibroblast or fibroblast-like cells situated in the sublining region of synovium. ${ }^{19} 212627$

The purpose of our study was to characterise synovial component cells based on their content of hEGF, by using immunohistochemistry. The results show that hEGF synthesised by the synovial lining type $B$ cell may be a potent factor in the stratification of synovial lining layer and perhaps the neovascularisation of rheumatoid synovium. The selective localisation of hEGF to the synovial lining layer may facilitate exact sorting of this population of cells.

\section{Materials and methods}

\section{SYNOVIAL SPECIMENS}

Samples of synovia were obtained during joint surgery from 20 patients with definite or classic seropositive rheumatoid arthritis, ${ }^{28}$ one with osteoarthritis, and three with normal traumatic joints. Both active and inactive rheumatoid tissues were included. Cartilage-pannus junction specimens were selected only from active cellular pannus of three patients. ${ }^{19}$ Tissue specimens were fixed in $2 \%$ paraformaldehyde, $0.075 \mathrm{M}$ lysine, and $0.01 \mathrm{M}$ sodium periodate solution overnight at $4^{\circ} \mathrm{C} .^{29} 30$

\section{IM MUNOHISTOCHEMISTRY OF hEGF}

For electron microscopy specimens cut in small pieces were washed with phosphate buffered saline pH $7 \cdot 2$ for at least 24 hours and reacted with rabbit anti-hEGF antisera at $4^{\circ} \mathrm{C}$ overnight. Anti-hEGF antisera were raised by immunising rabbits with hEGF, which was highly purified according to Cohen and Carpenter. ${ }^{31} 32$ Its specificity has been confirmed by us and by others (YH-1 in Ref 33) using radioimmunoassay against a panel of structurally related peptides, including mouse epidermal growth factor and platelet derived growth factor. ${ }^{32-34}$ Tissue specimens were washed with phosphate buffered saline for at least 24 hours, then reacted with the horseradish peroxidase conjugated IgG fraction of goat polyvalent antirabbit IgG $\mathrm{F}(\mathrm{ab})_{2}$ antibody (Cappel Laboratories, Downingtown, PA) at $4^{\circ} \mathrm{C}$ overnight. The specimens were washed for 48 hours, then reacted with diaminobenzidine- $\mathrm{H}_{2} \mathrm{O}_{2}$ solution for 30 minutes at room temperature, by a modification of the Graham and Karnovsky staining method, to minimise endogenous peroxidase reactivities. ${ }^{30}$ Specimens were then fixed with $1 \% \mathrm{OsO}_{4}$ for one hour at $4^{\circ} \mathrm{C}$, dehydrated in graded alcohol, and embedded in Epon 812. Sections $100 \mathrm{~nm}$ thick were cut with an LKB ultramicrotome and examined for peroxidase staining under Hitachi HS-9 electron microscope without counterstaining. Horseradish peroxidase staining was examined taking into account the penetration limit of the horseradish peroxidase-immunoglobulin complex, based on previous results. ${ }^{35}$

Tissue specimens fixed in the same manner were also examined under light microscope to obtain a wide view of them and to minimise bias due to observation of a restricted tissue field. Tissue specimens, cut approximately $4 \mathrm{~mm}$ in thickness, were embedded in Tissue-Tek (Lab-Tek Products, Naperville, Il) and snap frozen in isopentane, which was precooled in a dry ice-acetone bath. A thin section, $7 \mu \mathrm{m}$ in thickness, was cut and mounted on glass slides. It was considered that sufficient penetration of the horseradish peroxidase-immunoglobulin macromolecular complexes was obtained in a tissue section as thin as $7 \mu \mathrm{m}$ thick. ${ }^{35}$ The specimen was reacted with rabbit anti-hEGF antisera at room temperature for 30 minutes and then with horseradish peroxidase-goat antirabbit $\mathrm{IgG}$ for 30 minutes. After reacting with diaminobenzidine- $\mathrm{H}_{2} \mathrm{O}_{2}$, the tissue specimen was examined under photomicroscope without $\mathrm{OsO}_{4}$ treatment.

To confirm the specificity of hEGF staining tissue specimens were allowed to react either with nonimmune normal rabbit serum samples or rabbit di:tihEGF antisera preabsorbed with recombinant hEGF (GE002, Cosmobio Co Ltd, Tokyo, Japan). For preabsorption the amount of hEGF calculated from the results of radioimmunoassay was precoated on a Falcon No 3037 (Beckton-Dickinson and Co, Oxnard, California) Petri dish. Anti-hEGF antisera were then passed tl.rough these Petri dishes three times, each passage consisting of overnight incubation at $4^{\circ} \mathrm{C}$ in a humidified atmosphere. The supernatant thus obtained : :as used for hEGF staining. Anti-hEGF antisera passed through uncoated Petri dishes similarly three times were used as a positive control. Different histological variables, measured semiquantitatively with an arbitrary scale, were statistically compared with each other. ${ }^{36}$

Transforming growth factor $\beta$ purified from human platelets was purchased from Collaborative Research Inc, Lexington, MA, and human synthetic transforming growth factor $\alpha$ from Bachem Fine Chemicals Inc, Torrance, CA, respectively. The specificity of the antibody was examined by radioimmunoassay. ${ }^{32}$

\section{Results}

When hEGF staining was examined in a light microscope it was found to be localised almost 
822. Shiozawa, Shiozawa, Tanaka, et al
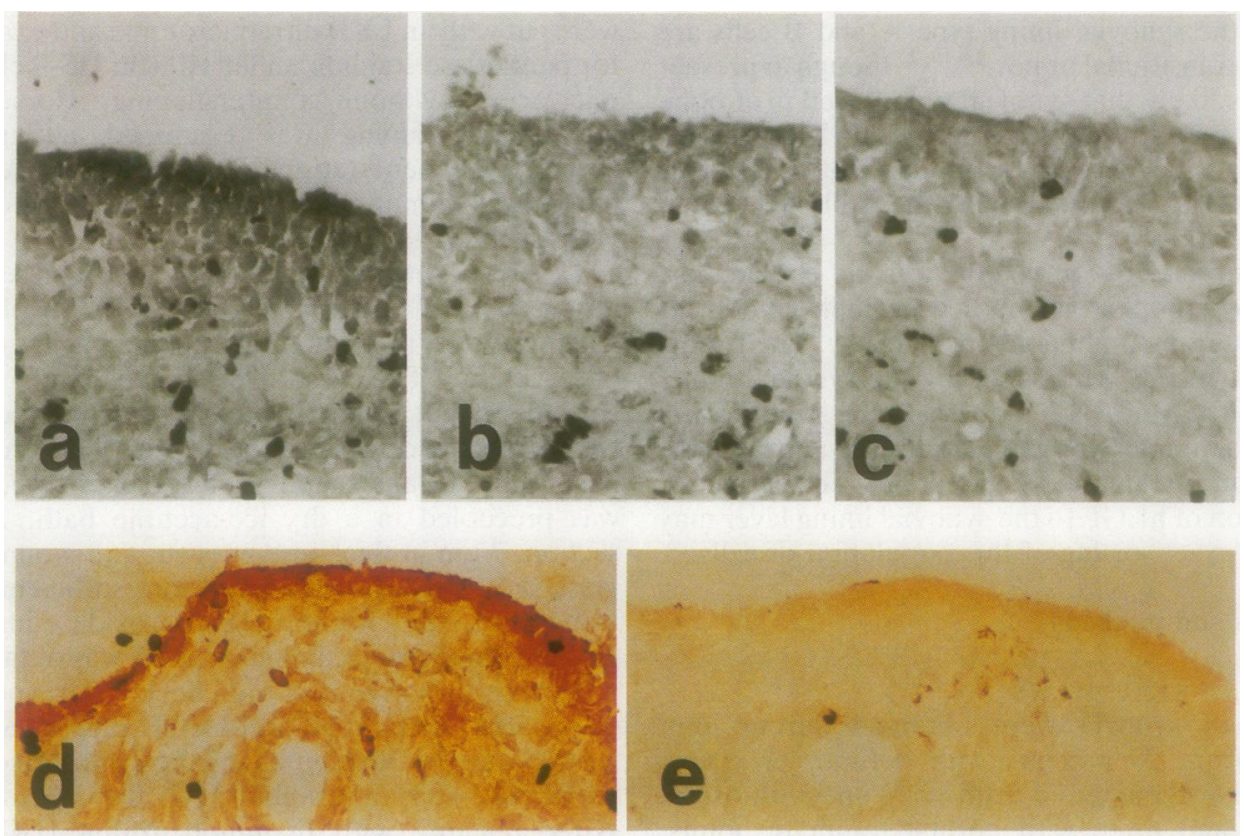

Fig. 1 Immunohistochemistry of rheumatoid synovium. (a) A frozen section, 7 um thick, stained with rabbit antihuman epidermal growth factor (anti-hEGF) antisera previously passed three times through uncoated Petri dishes, followed by staining with the horseradish peroxidase conjugated $\lg G$ fraction of goat polyvalent antirabbit $\operatorname{IgG} F(a b)_{2}$ antibody.

Localisation of antibody is visualised by diaminobenzidine reaction. Note that the stratified synovial lining layer is $h E G F$ positive. (b) Similar section stained with rabbit anti-hEGF passed three times through hEGF coated Petri dishes. Note the absence of $h E G F$ staining. (c) A section stained with non-immune normal rabbit sera as a control. (d) Another rheumatotd section stained with untreated rabbit anti-hEGF antisera. Note the intense $h E G F$ staining on the synovial lining layer.

Human epidermal growth factor is also weakly positive in the cells of sublining synovium. (e) A section similar to (d). stained尺 with non-immune normal rabbit sera.

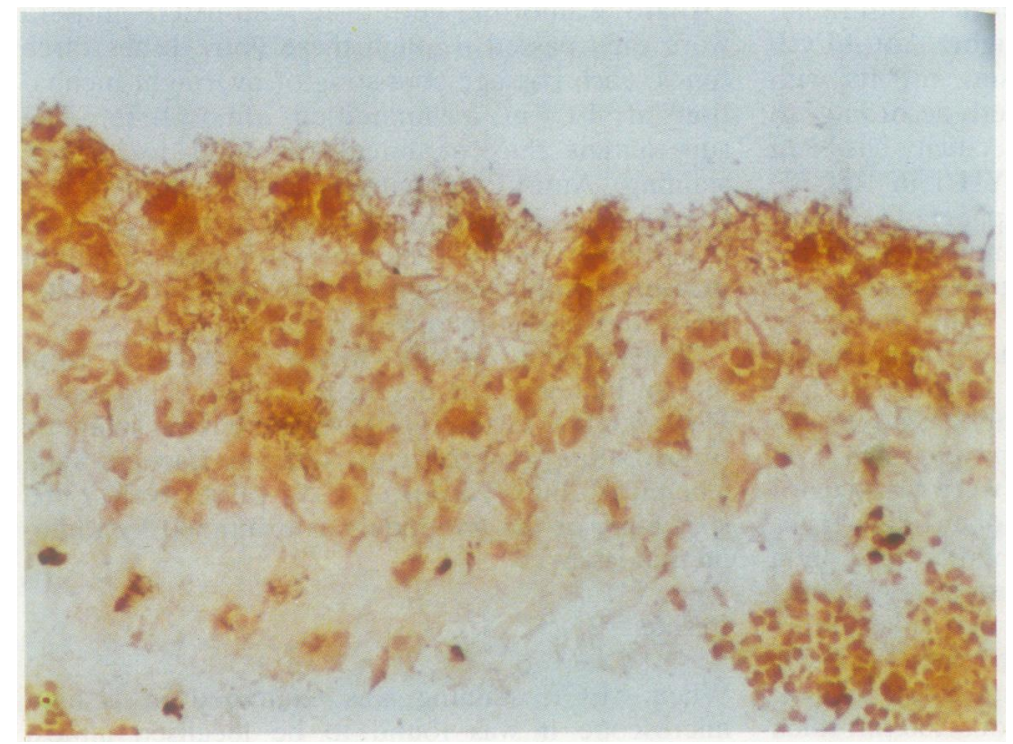

Fig. 2 Left side: microscopic view 0 of frozen section of traumatic synovium stained with rabbit antihuman epidermal growth factor (anti-hEGF) and horseradish peroxidase-antirabbit IgG antibodies similarly to Fig. $1 d$. N Sparsely distributed synovial lining $\underset{\mathrm{W}}{\mathrm{N}}$ cells are $h E G F$ positive. 


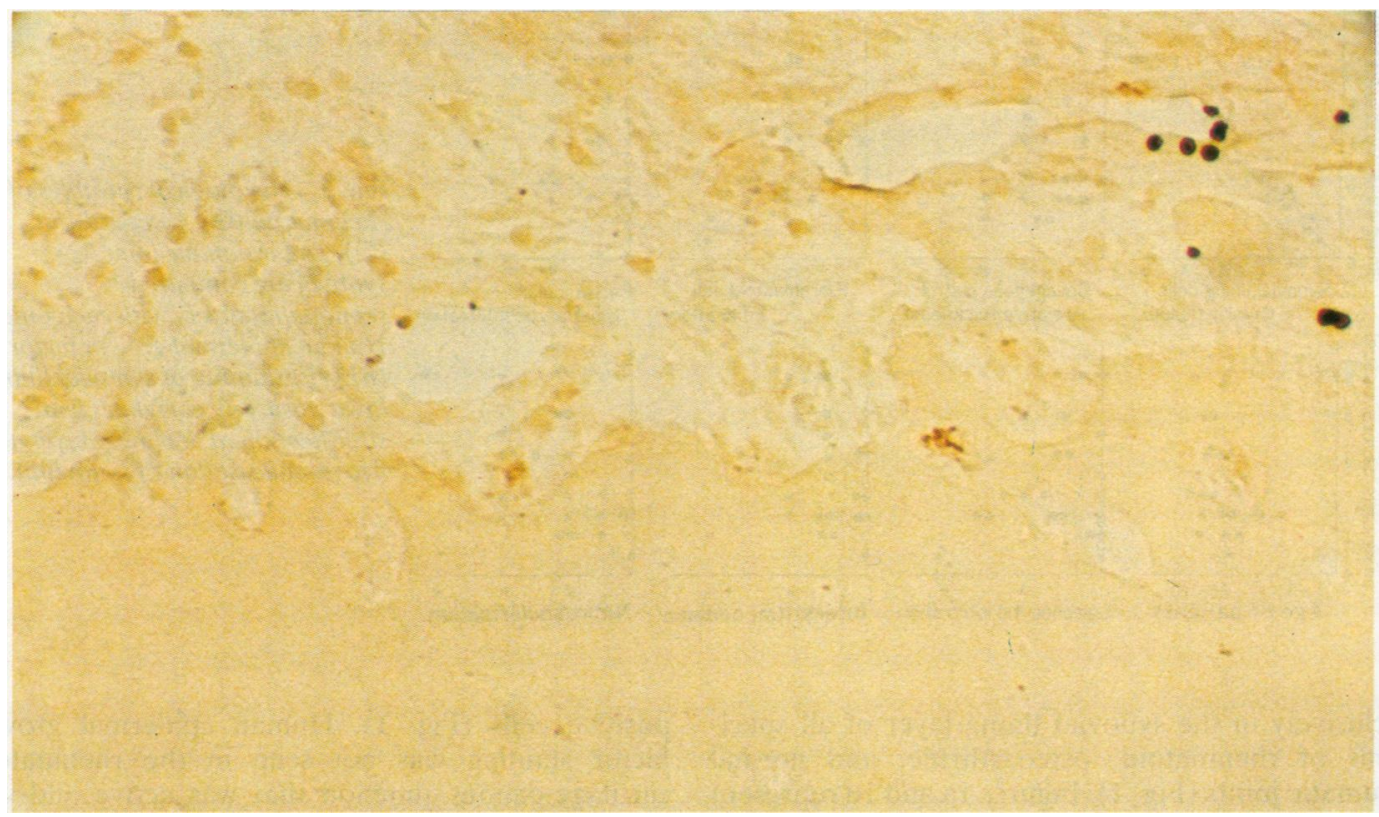

Fig. 3 Microscopic view of rheumatoid cartilage-pannus junction stained for human epidermal growth factor ( $h E G F)$ in a similar manner to Fig. $1 d$. Active cellular pannus with vessel formation is $h E G F$ negative.

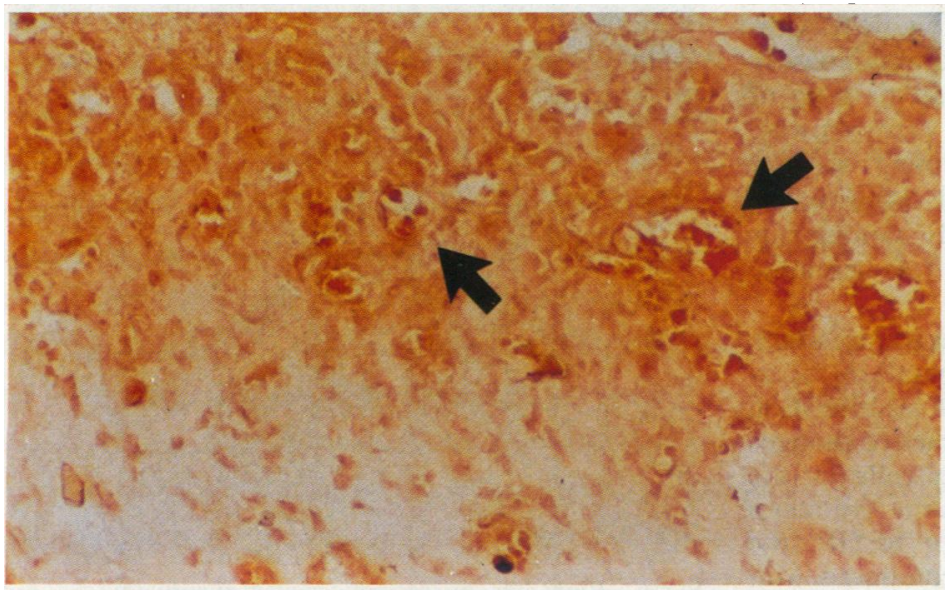

Fig. 4 Left side: microscopic view of rheumatoid synovium stained in a similar manner to Fig. 1d. Capillaries are seen infiltrating beneath human epidermal growth factor positive stratified synovial lining layer (arrow). 


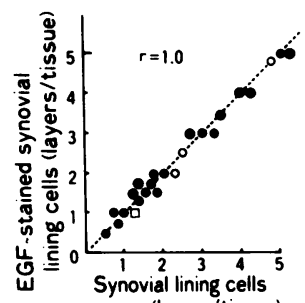
(layers/tissue)
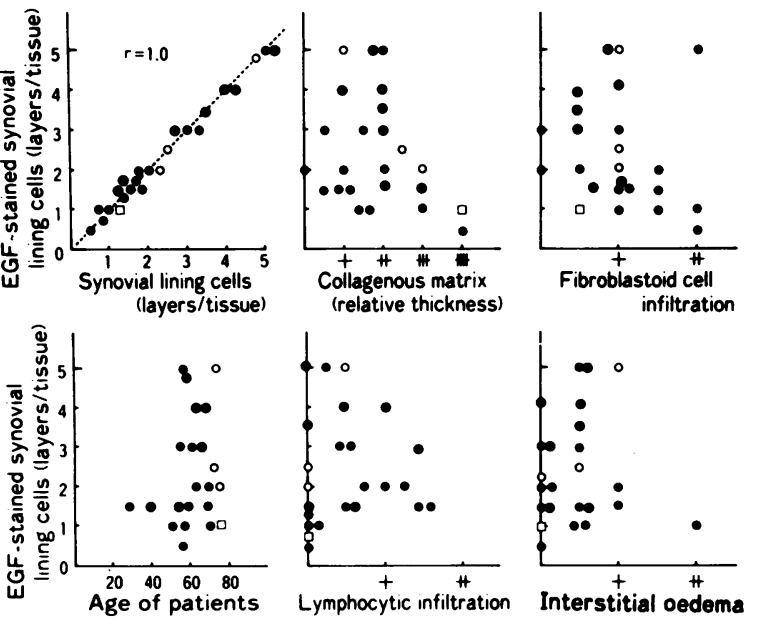

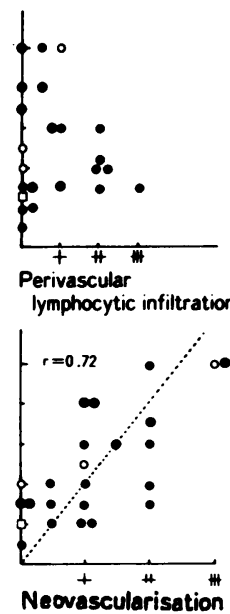

Fig. 5 Histological variables of rheumatoid (Q), osteoarthritic

$(\square)$, and traumatic joint $(\mathrm{O})$ synovia are compared semiquantitatively with each other. Human epidermal growth factor hEGF) staining of synovial lining layer positively correlates with stratification of the lining layer and $\vec{\omega}$ neovascularisation of synovium. exclusively in the synovial lining layer of all specimens of rheumatoid, osteoarthritic, and normal traumatic joints (Fig. 1). Figures 1a and 1d represent hEGF staining of rheumatoid synovia, in which stratified synovial lining cells were hEGF positive. The specificity of hEGF staining was confirmed by applying either non-immune normal rabbit serum samples (Figs 1c and e) or anti-hEGF antisera previously passed through coated Petri dishes (Fig. 1b). Figure 1a represents the positive control for Fig. 1b, in which the corresponding rheumatoid section was stained with anti-hEGF antisera previously passed through uncoated Petri dishes. Although the intensity of the staining was somewhat decreased by passing through uncoated Petri dishes, the specific staining was preserved (Fig. 1a). AntihEGF antisera were examined by radioimmunoassay and shown not to cross react with up to $1 \mu \mathrm{g}$ of transforming growth factor $\alpha$ or $\beta$ (not shown). Human epidermal growth factor staining was not absolutely restricted to the synovial lining layer; positive but substantially weak hEGF staining was occasionally observed in the cells of sublining synovium (Fig. 1d).

Synovial lining layer of the traumatic joints, which was expected to show normal inflammation, occasionally showed a certain degree of stratification (Fig. 2), probably because of minor reactive changes produced by trauma. Although the cells in the proliferating region of normal traumatic synovium such as Fig. 2 stained positively for hEGF, the intensity of the staining was weak compared with that of rheumatoid synovial lining layer. In addition, the non-proliferating region of normal synovium was weakly hEGF positive. In contrast, the rheumatoid synovium was densely packed with hEGF positive cells (Fig. 1). Human epidermal growthfactor staining was not seen in the rheumatoido cartilage-pannus junction that was active and cel$\operatorname{lular}^{19}$ (Fig. 3). Because a tissue section as thin ad

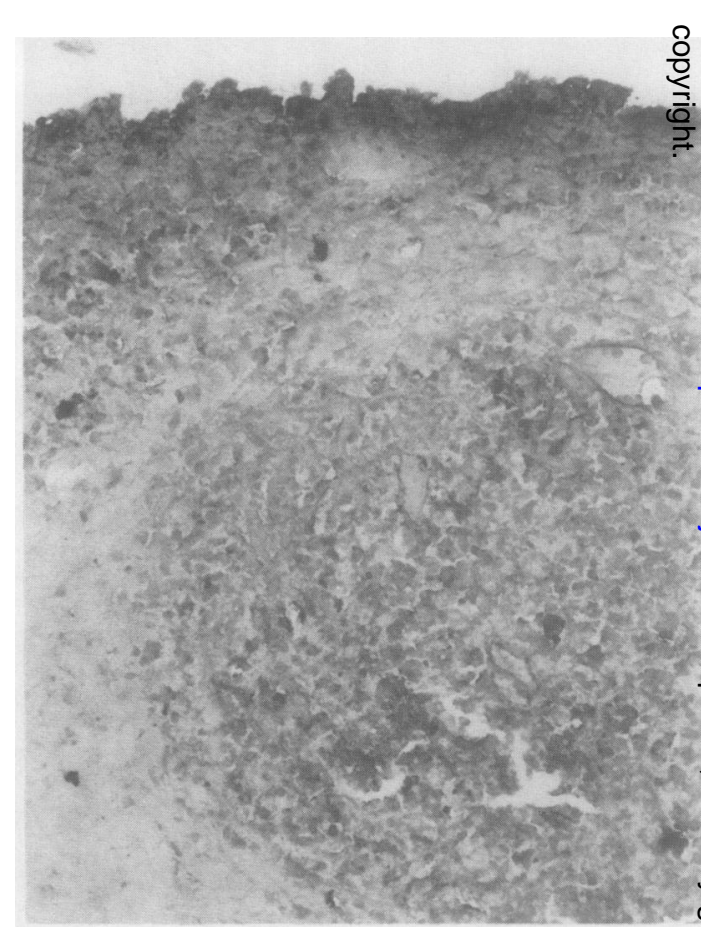

Fig. 6 Right side: microscopic view of rheumatoid synovium stained in a similar manner to Fig. Id.

A lymphocyte cluster is weakly human epidermal growth factor ( $h E G F)$ positive. Note the intense $h E G F$ staining on the stratified synovial lining layer. 
$7 \mu \mathrm{m}$ was used to confirm the absence of staining a false negative result due to inadequate penetration of antibodies was unlikely.

When different histological variables were compared with each other a linear correlation existed between the relative amount of hEGF positive synovial lining cells and the degree of stratification of the lining layer $(r=1)$ (Fig. 5). Human epidermal growth factor staining of the synovial lining layer did not correlate with the extent of lymphocyte infiltration or perivascular accumulation of lymphocytes.
Instead, there existed a positive correlation between hEGF staining of the synovial lining layer and the degree of neovascularisation in the rheumatoid synovium $(r=0.72)$ (Fig. 5). Figure 4 shows that rheumatoid synovial lining layer, which is stratified and hEGF positive, is heavily infiltrated with small blood vessels.

Some, but not all of the clusters of lymphocytes of rheumatoid synovium were hEGF positive, though the intensity of the staining was considerably weaker than that of the synovial lining layer (Fig. 6). The
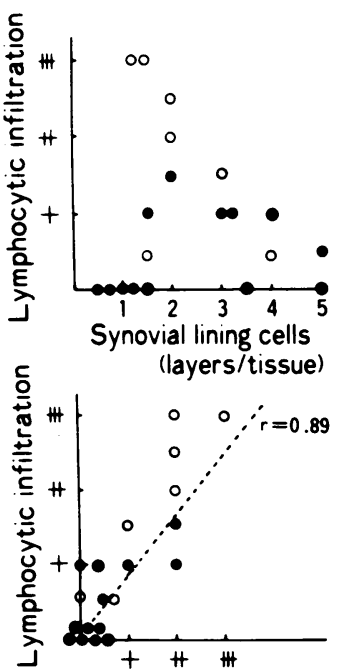

Perivascular lymphocytic infiltration
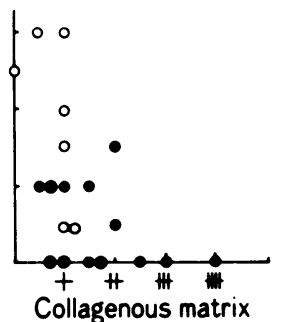

(relative thickness)

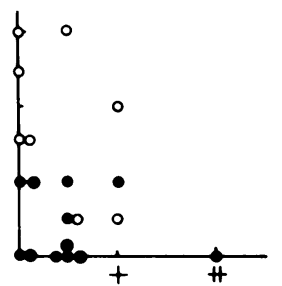

Interstitial oedema

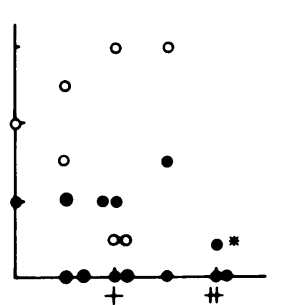

Fibroblastoid cell infiltration

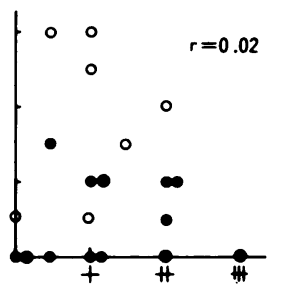

Neovascularisation
Fig. 7 Correlation between lymphocyte infiltration and other histological variables. The cluster of lymphocytes is either human epidermal growth factor ( $h E G F$ ) positive (O) or hEGF negative (O). Lymphocyte infiltration correlates positively with perivascular accumulation of lymphocytes.
Fig. 8 Immunoelectron microscopic view of a rheumatoid synovial lining fibroblast-like (type B) cell, stained with rabbit antihuman epidermal growth factor (anti-hEGF) and horseradish peroxidase-antirabbit $\operatorname{IgG}$ antibodies and observed without counterstaining. Cytoplasm of the type B cell is diffusely hEGF positive. Human epidermal growth factor is localised to rough endoplasmic reticulum (inset). Staining by hEGF is weak in the area of Golgi apparatus (arrow) and absent in mitochondria (inset, arrow head). 

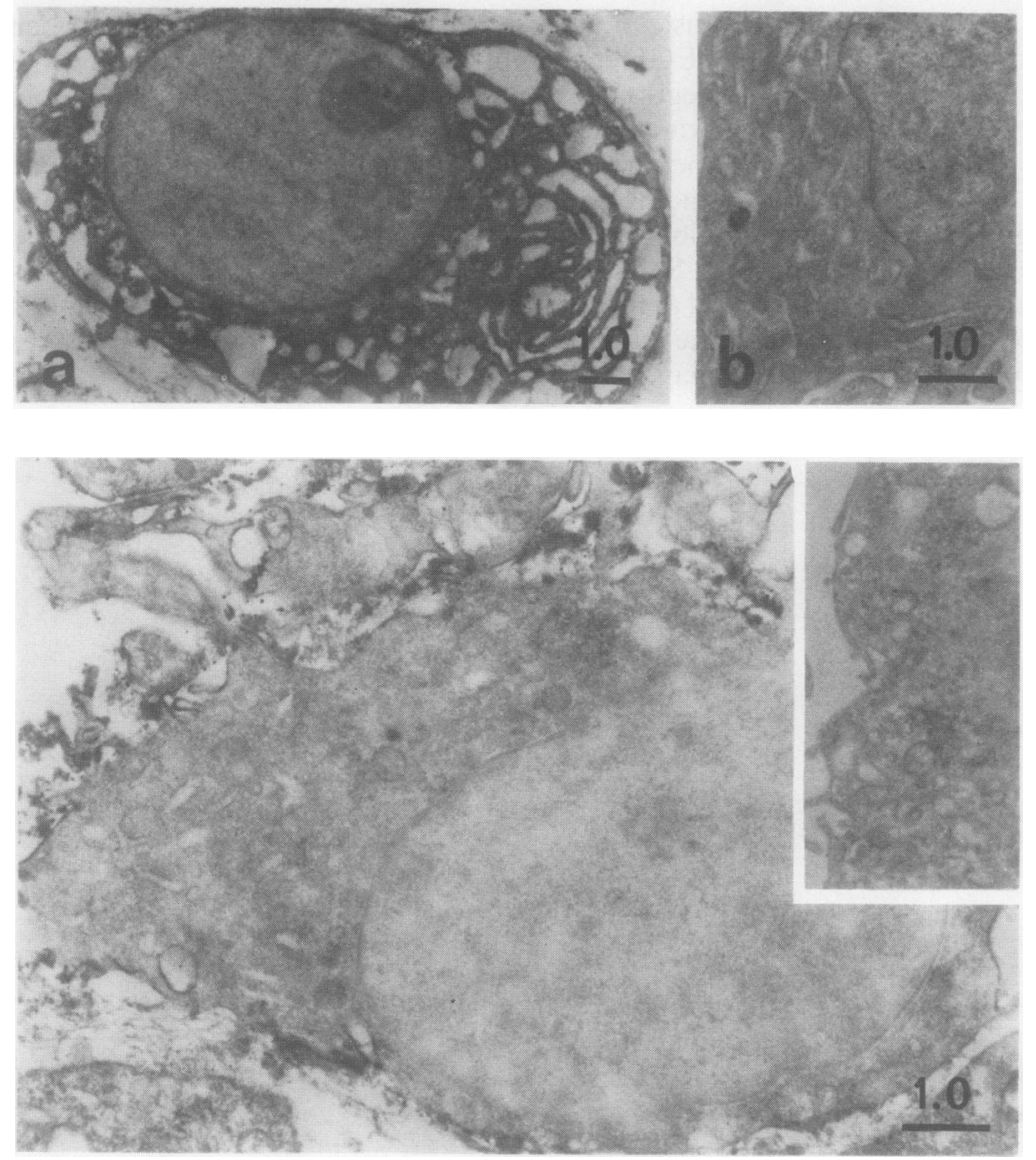

Fig. 9 Another immunoelectron microscopic view of a rheumatoid synovial lining type $B$ cell. (a) Human epidermal growth factor ( $h E G F)$ is positive in the cytoplasm containing many dilate rough endoplasmic reticula.

(b) A control section stained with $\stackrel{\triangleright}{\varnothing}$ non-immune normal rabbit serum samples. Note the absence of $h E G F$ staining.

Fig. 10 Immunoelectron microscopic view of a rheumatoid synovial lining macrophage-like (type A) cell, stained similarly to Fig. 8. The cell surface of a type $\bar{P}$ cell is partially human epidermal growth factor ( $h E G F$ ) positive. Control section stained with nofimmune normal rabbit serum 우 samples is hEGF negative (ins

extent of lymphocyte infiltration correlated positively with perivascular accumulation of lymphocytes $(r=0.89)$, whereas hEGF staining of lymphocytes did not correlate with the degree of neovascularisation in the rheumatoid synovium (Fig. 7).

Under electron microscope hEGF was localised to the cytoplasm of synovial lining fibroblast-like (type B) cells (Figs 8 and 9). Human epidermal growth factor staining was ultrastructurally localised to rough endoplasmic reticulum, sparing mitochondria, of the cell (Fig. 8). Staining on Golgi apparatus was less obvious. The fibroblast-like cell in the sublining synovium was also hEGF positive, but the intensity of the staining was very weak as compared with that of the synovial lining fibroblastlike cell. In contrast, hEGF staining was observed only on the cell surface of synovial lining macrophage-like (type A) cells (Fig. 10).

\section{Discussion}

Human epidermal growth factor and transforming growth factor $\alpha$ display a $35 \%$ homology in their amino acid sequence, and biological effects of these factors in vitro are often indistinguishable ${ }^{37-39}$ Both substances share the same epidermal growtie. factor receptor for their biological signal trans尺 duction. In this study we confirmed by radióimmunoassay that anti-hEGF antisera did not cros: react with transforming growth factors $\alpha$ or $\beta$. In 2 tissue section hEGF treatment effectively absorbe $\$$ the hEGF staining.

Our study shows that hEGF is specifically localise $\bar{\Phi}$ to the synovial lining layer of rheumatoid, osteo ${ }^{-}$ arthritic, and normal traumatic joints. In particular hEGF staining was dense at the rheumatoid syno? vium, the staining increasing linearly according to 
the degree of stratification of the synovial lining layer. In addition, the ultrastructural localisation of hEGF to the cytoplasm, especially to rough endoplasmic reticulum and Golgi apparatus of the cell, fulfils the morphological criteria of synthesis and secretion of hEGF by the synovial lining fibroblastlike (type B) cell. Because only the cell surface of macrophage-like (type A) cells was also hEGF positive we may speculate that hEGF secreted from a type B cell stimulates a type A cell and in this way contributes to the stratification of synovial lining layer. The synthesis and secretion of hEGF through rough endoplasmic reticulum and Golgi apparatus as shown in this study are compatible with the established pathway for other secretory proteins. ${ }^{40}$ Because hEGF staining was weak in the Golgi apparatus, however, it appears that not all the synthesised hEGF is actually secreted. This may be exemplified by the illustration of a kind of frustrated secretion by the type B cell as in Fig. 9. Together these findings suggest that hEGF is at least partially responsible for the pathogenesis of stratification of the synovial lining layer in rheumatoid arthritis. It is also possible that one or more factors other than hEGF operate in concert with hEGF in this process as hEGF is a progression factor for the cell proliferation.

There was a positive correlation between hEGF staining of the synovial lining layer and the degree of neovascularisation in the rheumatoid synovium. Neovascularisation, however, showed no correlation with the extent of lymphocyte infiltration or of hEGF staining of lymphocytes. Lymphocyte infiltration or hEGF staining of lymphocytes also did not correlate with hEGF staining of the synovial lining layer, whereas the lymphocyte infiltration correlated positively with the extent of perivascular accumulation of lymphocytes. These findings indicate that factor(s) other than hEGF must be responsible for attracting lymphocytes to the rheumatoid synovium. It appears that hEGF as expressed on lymphocytes is the result of in situ activation of lymphocytes rather than derived from the synovial lining layer. The results also suggest that hEGF synthesised in the synovial lining layer could be responsible for the development of neovascularisation in the rheumatoid synovium, whereas the lymhocytes are clearly not responsible for neovascularisation. Although this finding needs confirmation, the result is compatible with recent results on the angiogenic property of hEGF. 41

The differential localisation of hEGF in type A and $B$ cells found in this study is further evidence for the difference between synovial lining fibroblast-like (type B) and macrophage-like (type A) cells. The synovial lining type B cells are also distinct from fibroblasts situated in the sublining synovium because the amount of hEGF stained in the synovial lining type B cell was distinctly greater than that in the sublining fibroblasts, even when examined in the same tissue section. As both types of cells more or less synthesise hEGF, however, it is still possible that the synovial lining fibroblast-like (type B) cell is derived from sublining fibroblasts or fibroblast-like cells by their transformation, as suggested by Fassbender et al. ${ }^{21}$ If this is the case it appears that the synthesis of hEGF may somehow be enhanced in contact with synovial fluid components. As a result of these findings we propose that synovial lining type A and B cells could now be reclassified based on their content of hEGF. Exclusive localisation of hEGF to the synovial lining layer as found in this study enables us to sort the cells of the synovial lining layer selectively. The lack of specific markers for the synovial lining layer has long been a major obstacle in this field of study.

We thank Professor Morris Ziff, Dallas, for his kind advice and continuing help. This work was supported by Japan Ministry of Education and welfare grant 62570288 to SS.

\section{References}

1 Kulka J P, Bocking D, Ropes M W, Bauer W. Early joint lesions of rheumatoid arthritis. Report of eight cases, with knee biopsies of lesions of less than one year's duration. Archives of Pathology, 1955; 59: 129-50.

2 Schumacher H R, Kitridou R C. Synovitis of recent onset. A clinicopathologic study during the first month of disease. Arthritis Rheum 1972; 15: 465-85.

3 Bywaters E G L. The early radiological signs of rheumatoid arthritis. Bull Rheum Dis 1960; 11: 231-4.

4 Shimizu S, Shiozawa S, Shiozawa K, Imura S, Fujita T. Quantitative histologic studies on the pathogenesis of periarticular osteoporosis in rheumatoid arthritis. Arthritis Rheum 1985; 28: 25-31.

5 Carpenter G, Cohen S. Epidermal growth factor. Annual Review of Biochemistry 1979; 48: 193-216.

6 Tashjian A H Jr, Levine L. Epidermal growth factor stimulates prostaglandin production and bone resorption in cultured mouse calvaria. Biochem Biophys Res Commun 1978; 85: 966-75.

7 Hirata Y, Uchihashi M, Nakashima H, Fujita T, Matsukura S, Matsui K. Specific receptors for epidermal growth factor in human bone tumour cells and its effect on synthesis of prostaglandin $\mathrm{E}_{2}$ by cultured osteosarcoma cell line. Acta Endocrinol (Copenh) 1984; 107: 125-30.

8 Shupnik M A, Ip N Y-Y, Tashjian A H Jr. Characterization and regulation of receptors for epidermal growth factor in mouse calvaria. Endocrinology 1980; 107: 1738-46.

9 Shupnik M A, Tashjian A H Jr. Functional receptors for epidermal growth factor on human osteosarcoma cells. J Cell Physiol 1981; 109: 403-10.

10 Førre $\emptyset$, Thoen $J$, Lea $T$, et al. In situ characterization of mononuclear cells in rheumatoid tissues, using monoclonal antibodies: no reduction of T8-positive cells or augmentation in T4-positive cells. Scand J Immunol 1982; 16: 315-9.

11 Poulter L W, Duke O, Hobbs S, Janossy G, Panayi G. Histochemical discrimination of HLA-DR positive cell populations in the normal and arthritic synovial lining. Clin Exp Immunol 1982; 48: 381-8. 
12 Shiozawa S, Shiozawa K. Fujita T. Presence of HLA-DR antigen on synovial type $A$ and $B$ cells: an immunoelectron microscopic study in rheumatoid arthritis, osteoarthritis and normal traumatic joints. Immunology 1983; 50: 587-94.

13 Iguchi T, Kurosaka M, Ziff M. Electron microscopic study of HLA-DR and monocyte/macrophage staining cells in the rheumatoid synovial membrane. Arthritis Rheum 1986; 29: 600-13.

14 Klareskog L, Forsum U, Kabelitz D, et al. Immune functions of human synovial cells: phenotypic and $\mathrm{T}$ cell regulatory properties of macrophage-like cells that express HLA-DR. Arthritis Rheum 1982; 25: 488-501.

15 Tiku M L, Teodorescu M. Skosey J L. Immunobiological function of normal rabbit synovial cells. Cell Immunol 1985; 91 : 415-24.

16 Shimizu S, Shiozawa S, Shiozawa K, et al. The restoration of proliferation and differentiation of peripheral blood mononuclear non-adherent cells into immunoglobulin-secreting cells by autologous synovial adherent cells from patients with rheumatoid arthritis. Virchows Arch /Cell Pathol] 1988; 54: $350-6$.

17 Barland P, Novikoff A B, Hamerman D. Electron microscopy of the human synovial membrane. J Cell Biol 1962; 14: 207-20.

18 Hirohata K, Kobayashi I. Fine structures of synovial tissues in rheumatoid arthritis. Kobe J Med Sci 1964; 10: 195-225.

19 Shiozawa S, Shiozawa K. Fujita T. Morphologic observations in the early phase of the cartilage-pannus junction. Light and electron microscopic studies of active cellular pannus. Arthritis Rheum 1983; 26: 472-8.

20 Norton W L. Ziff M. Electron microscopic observations on the rheumatoid synovial membrane. Arthritis Rheum 1966; 9: 589-610.

21 Fassbender H G, Simmling-Annefeld M. Stofft E. Transformation der Synovial Zellen bei rheumatoider Arthritis. Verh Dtsch Ges Pathol 1980; 64: 193-212.

22 Hogg N, Palmer D G, Revell P A. Monoclonal phagocytes of normal and rheumatoid synovial membrane identified by monoclonal antibodies. Immunology 1985: 56: 673-81.

23 Palmer D G, Selvendran Y, Allen C. Revell P A. Hogg N. Features of synovial membrane identified with monoclonal antibodies. Clin Exp Immunol 1985; 59: 529-38.

24 Dreher R. Origin of synovial type A cells during inflammation: an experimental approach. Immunobiology 1982; 161: 232-45.

25 Edwards J C W. Willoughby D A. Demonstration of bone marrow derived cells in synovial lining by means of giant intracellular granules as genetic markers. Ann Rheum Dis 1982; 41 : 177-82.
26 Okada Y, Nakanishi I, Kajikawa K. Ultrastructure of the mouse synovial membrane: development and organization of. the extracellular matrix. Arthritis Rheum 1981; 24: 835-43.

27 Okada Y, Nakanishi I, Kajikawa K. Repair of the mouse synovial membrane after chemical synovectomy with osmiunf tetroxide. Acta Pathol Jpn 1984: 34: 705-14.

28 Ropes M W, Bennett G A. Cobb S, Jacox R. Jessar R A. 195 revision of diagnostic criteria for rheumatoid arthritis. Bu/s Rheum Dis 1958; 9: 175-6.

29 McLean I W, Nakane P K. Periodate-lysine-paraformaldehyd fixative: a new fixative for immunoelectron microscopy J Histochem Cytochem 1974; 22: 1077-83.

30 Shiozawa S, Williams R C Jr, Ziff M. Immunoelectrof microscopic demonstration of prostaglandin $E$ in rheumatoid synovium. Arthritis Rheum 1982; 25: 685-93.

31 Cohen S, Carpenter G. Human epidermal growth factor isolation and chemical and biological properties. Proc Na寄 Acad Sci USA 1975: 72: 1317-21.

32 Hirata Y, Moore G W, Bertagna C, Orth D N. Plasmå concentrations of immune reactive epidermal growth facto $\vec{b}$ (urogastrone) in man. J Clin Endocrinol Metab 1980; 50: 440-4\%

33 Kasselberg A G, Orth D N, Gray M E. Stahlman M TO Immunocytochemical localization of human epidermal growtb factor/urogastrone in several human tissues. J Histochem Cytochem 1985: 33: 315-22.

34 Oka Y. Orth D N. Human plasma epidermal growth factor $\beta$-urogastrone is associated with blood platelets. J Clin Invesf 1983; 72: 249-59.

35 Shiozawa S. Jasin H E. Ziff M. Absence of immunoglobulins i rheumatoid cartilage-pannus junctions. Arthritis Rheum 1980 23: 816-21.

36 Hoel P G. Elementary statistics. New York: Wiley, 1966.

37 Carpenter G. Zendegui J G. Epidermal growth factor receptor, and related proteins. Exp Cell Res 1986; 164: 1-

38 Massagué J. Epidermal growth factor-like transforming growt factor. II. Interaction with epidermal growth factor receptors if human placenta membranes and A431 cells. J Biol Chem 19830 258: $13614-20$.

39 Tam J P. Marquardt H. Rosberger D F. Wong T W. Todaro G Q Synthesis of biologically active rat transforming growth factor Nature 1984: 309: 376-8.

40 Palade G. Intracellular aspects of the process of protein synthesis. Science 1975: 189: 347-58.

41 Schreiber A B. Winkler M E. Derynck R. Transforming growt factor- $\alpha$ : a more potent angiogenic mediator than epidermaty growth factor. Science 1986: 232: 1250-3. . (2) 